\section{Surveying sexual attitudes}

SIR-S. J. Gurman writes to discuss the problem of obtaining valid data on sexual attitudes and lifestyles through survey methods (Nature 342, 12; 1989). He uses an analogy from natural science to make the point that the mean number of heterosexual partners should be equal for men and women. In mathematical models of the transmissions dynamics of sexually transmitted diseases, this constraint plays a central role in model formulation and analysis (see AIDS 3, 333-346; 1989). However, the constraint mentioned by Gurman holds only for a closed population without immigration and emigration throughout a time period in excess of the maximum life span of sexual activity. In our oral presentation of the data, on which the News and Views article in Nature was based (Nature 341, 181; 1989), we were at pains to point out the difficulties inherent in interpretation (incidentally, the mean number of 'lifetime partners' was misreported in the article; our figures show a smaller disparity between means for men and women).

Our data show high variability and a very skewed distribution in reported number of sexual partners. Not surprisingly, there is less variability in numbers of partners reported over short time periods, for example one month, but this increases markedly with the length of time interval for which numbers of sexual partners are reported (up to "in your lifetime (so (ar)").

The estimates of the mean lifetime partners for men are heavily influenced by the very small proportion (less than 1 per cent) reporting high numbers of partners $(>100)$. Of equal interest is the overall pattern of distribution of numbers of partners. Sample bias is of particular concern in the estimation of the population mean or variance - variance is related to the mean by a power law relationship, with a power in excess of 3 (Nature 333, 514-519; 1988). In order adequately to represent the variability in sexual behaviour, sample size, as well as selection, is important. In the feasibility study, the sample size was approximately 1,000 , in the full study it will be around 20,000 .

Both increasing time and increasing numbers of partners lead to greater difficulties of recall, and therefore estimates of lifetime partners are inevitably the most unstable. We found much greater similarity between men and women in patterns and numbers of partners when shorter finite time intervals were considered.

'Lifetime partner' estimates for each individual do not refer to a finite time period. They include raw data for all ages and refer to partners since first intercourse to the present time. They therefore report numbers of partners 'thus far'. These raw data take no account of age structure of the sample, age mixing, generational and demographic changes, or international mobility of populations, all of which affect patterns of sexual behaviour. Our data show that men choose female partners who are, on average, younger than themselves. Thus the age distribution of women in our sample is not necessarily representative of the age distribution of the women partners of the men in this sample (and vice versa).

The quantitative study of human sexual relationships is as yet a little-explored area of research and the methodology is still being developed. In interpreting the data, caution will be uppermost in our minds. While the analogy to be drawn between the behaviour of chemical bonds and human partnerships is useful to evaluate data on patterns of sexual behaviour, there is a complex set of factors influencing patterns of sexual behaviour and mixing on which we hope that our main study will shed further light.

University College and Middlesex

School of Medicine

London W1, UK

J. WADSWORTH

St Mary's Hospital Medical School, London W2, UK

J. FIELD

Social \& Community Planning Research, London EC1, UK

Health Education Authority,

K. WELLINGS

London W1, UK

Imperial College of Science

\& Technology,

London SW7, UK

\section{Fruits of the forest}

SIR - In their Commentary article (Nature 339, 655-656; 1989), Peters and colleagues show that exploitation of non-wood resources in the Amazon rainforest, especially fruits, is far more economically rewarding than timber extraction. Therefore, sustainable use of these resources might provide an enticing argument against timber operations and an important step towards conserving the Amazon.

Current methods of harvesting many Amazonian fruits are alarmingly destructive, however. The most valuable fruiting trees, the palms, are cut down and killed in order to collect the fruit, because their physical structure makes climbing virtually impossible. Palm trees that are excessively harvested in this manner include Mauritia flexuosa, Mauritiella peruviana and Jessenia bataua.

Our studies, yet to be published, show that local inhabitants in Peru use palm fruits in a non-renewable manner that may be more detrimental than selective timbering. This is because large numbers of fruiting trees are permanently removed from the rainforest ecosystem just as they are beginning to be productive, whereas timber trees are normally cut in the nonfruiting state. Local inhabitants will not cut palm trees that grow on their small private plots, but will collect the fallen fruits and use them for household consumption. It is fruit from the vast areas of government-owned forests that are collected for commercial sale, and these trees that are cut during the harvest.

Cutting of palm trees also decreases the populations of ungulates and large rodents that rely on palm fruits for food. Reduced mammal populations result in diminishing returns of game meat for subsistence hunters and lower protein intake for local people. Unfortunately, until alternative non-destructive methods of harvesting fruits can be developed, there is no basis for arguing for fruit rather than timber as an economic resource in the Amazon.

RICHARD E. BODMER TULA G. FANG

Large Animal Research Group,

Department of Zoology,

University of Cambridge,

Cambridge CB3 ODT, UK

LUIS MOYA

Ministerio de Agricultura,

Region Agraria XXII-Loreto, Apt 621,

Iquitos, Loreto, Peru

\section{MIT in the red}

SIR-I write to clear up two misstatements referring to me in Seth Shulman's News report "MIT in the red" (Nature 341, 558; 1989).

To begin with, I may be thought of as a critic of excessive or misguided US strategic nuclear weapons procurements, but not of "MIT's reliance on military research dollars". I know of no evidence that Department of Defense funding has distorted academic research at Massachusetts Institute of Technology (MIT), and I have never said that.

Second, the "high level" meeting Shulman refers to has been called for the purpose of exploring ways to redeploy to the civilian sector some of the US research and development resources now used in weapons' development, in order to create an environmental technology base and to improve US industrial competitiveness. The meeting will be held at the American Academy of Arts and Sciences, and has nothing whatsoever to do with research at MIT.

KOSTA TSIPIS

Program in Science and Technology for International Security,

Massachusetts Institute of Technology, Cambridge, Massachusetts 02139, USA 